\title{
Animal models have little to teach us about Type 1 diabetes: 2. In opposition to this proposal
}

\author{
E. H. Leiter ${ }^{1}$ - M. von Herrath ${ }^{2}$ \\ 1 The Jackson Laboratory, Bar Harbor, Maine, USA \\ ${ }^{2}$ La Jolla Institute for Allergy and Immunology, San Diego, California, USA
}

The contrarians have to agree with their opponents that animal models in general, and rodent models of Type 1 diabetes in particular, are imperfect reflections of human disease [1]. This is the inevitable consequence of an evolutionary separation of over 65 million years. While pointing out the numerous differences that distinguish human from rodent immune systems, Mestas and Hughes [2] note that "after all, most of us do not live with our noses a half-inch off the ground." Clearly, divergent evolution in genera occupying different niches argues against using a mouse or rat model of spontaneous Type 1 diabetes as an exact blueprint for disease in humans. There are, however, sufficient similarities between the aetiopathogenesis of Type 1 diabetes in humans, mice and rats to justify the efforts devoted to animal research (Table 1). While there are significant differences between the various rodent models, this heterogeneity surely carries important lessons for understanding the potential heterogeneity underlying this complex disease in humans.

The major rodent models of spontaneous Type $1 \mathrm{di}$ abetes are the Nonobese Diabetic (NOD) mouse and

Received: 30 June 2004 / Accepted: 10 August 2004

Published online: 19 October 2004

(C) Springer-Verlag 2004

E. H. Leiter ( $)$

The Jackson Laboratory, 600 Main St., Bar Harbor, Maine,

USA

E-mail: ehl@jax.org

Tel.: +1-207-2886370, Fax: +1-207-2886077

M. von Herrath (凶)

La Jolla Institute for Allergy and Immunology,

10355 Science Ctr. Drive, San Diego, California, USA

E-mail: matthias@liai.org

Tel.: +1-858-5583571, Fax: +1-858-5583579

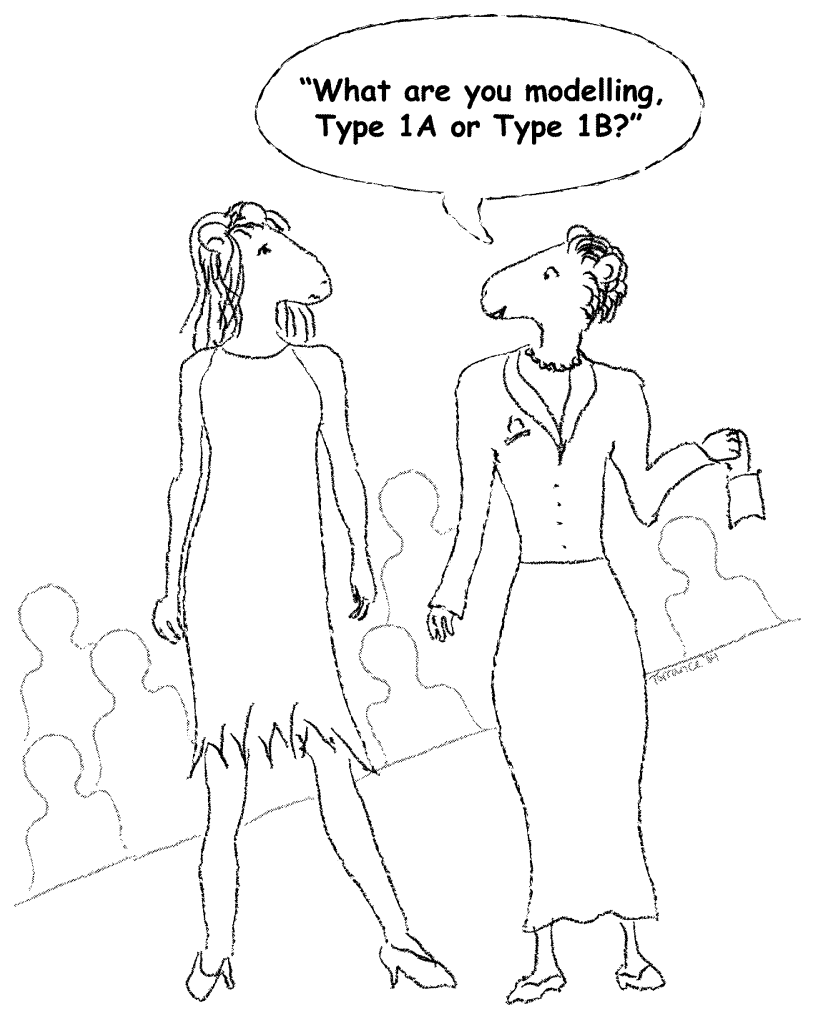

Fig. 1.

the BioBreeding (BB) rat. The latter includes both the T-lymphopenic diabetes-prone stock and the non-lymphopenic diabetes-resistant stock; diabetes can be induced in the latter by manipulating the immune system with transient $\mathrm{T}$ cell depletion combined with either a simulated viral challenge (poly I:C) or actual infection with Kilham rat virus or cytomegalovirus [3]. More recently, additional strains of inbred rats have been selected for Type 1 diabetes development, notably the Komeda diabetes-prone (KDP) rat in Japan [4], and the LEW.1AR1 rat in Germany [5]. 
Table 1. Comparison of insulin-dependent diabetes in humans, mice and rats

\begin{tabular}{|c|c|c|c|c|}
\hline Characteristic & Humans & $\begin{array}{l}\text { NOD } \\
\text { mice }\end{array}$ & $\begin{array}{l}\text { Lymphopenic BB } \\
\text { diabetes-prone } \\
\text { rats }^{\mathrm{a}}\end{array}$ & $\begin{array}{l}\text { Non-lymphopenic BB } \\
\text { diabetes-resistant } \\
\text { (inducible) rats }\end{array}$ \\
\hline Complex polygenic control & + & + & Oligogenic & Oligogenic \\
\hline Environmental effects on gene penetrance & Probable & + & + & + \\
\hline Disease transmissible via bone marrow & + & + & + & $?$ \\
\hline Defective peripheral immunoregulation & + & + & + & + \\
\hline Humoral reactivity to beta cells & + & + & - & $?$ \\
\hline Endogenous retroviral genes expressed in beta cells & - & + & - & $?$ \\
\hline Diabetic ketoacidosis if untreated & + & Mild & + & + \\
\hline Sex bias & - & + & - & - \\
\hline Successful intervention therapies & In progress & + & + & + \\
\hline
\end{tabular}

a Thanks to J. Mordes, University of Massachusetts Medical School (Worcester, Mass., USA) for advice regarding rat phenotypes

What are the common features that make studies of these various models so compelling? And what do the features distinguishing the various models tell us about the human disease(s)? With regard to shared immunogenetic features, the MHC class II region is a major genetic determinant of Type 1 diabetes susceptibility in all these rodent models, as in humans. With regard to immunopathophysiology, it is clear that Type 1 diabetes is a T-cell-mediated disease in all the rodent models, with pathogenic contributions from $\mathrm{B}$ lymphocytes, primarily as antigen-presenting cells rather than as autoantibody producers. In the NOD mouse and the diabetes-prone $\mathrm{BB}$ rat, the disease can be transmitted by haemopoietic stem cell transfer from susceptible donors, and prevented by bone marrow stem cell replacement from resistant strains. The knowledge that the genes contributing susceptibility to Type 1 diabetes are expressed at the haemopoietic stem cell level has long-term implications for prevention in humans [6]. Although the non-MHC genes contributing to diabetes susceptibility in the mouse and rat models are not the same, and those in the rat have yet to find a human susceptibility orthologue, they are nonetheless all implicated in control of $\mathrm{T}$ cell function. For example, a major NOD susceptibility modifier may be a specific polymorphism in the $\mathrm{T}$ cell regulatory $\mathrm{Ctla} 4$ gene (reflecting a polymorphic human CTLA4 candidate for IDDM12) [7]. In the BB diabetes-prone rat, the diabetes-susceptible environment is established in part by a defect in the Ian $4 L 1$ gene. This T-cell-specific gene regulates mitochondrial integrity and is required for T cell survival [8]. In the KDP rat, diabetogenesis is associated with defects in yet another gene, Cblb [9], the normal function of which, like that of Ctla4 in the mouse, is to downregulate $\mathrm{T}$ cell activation. Neither of the two rat nonMHC genes have as yet found human associations in studies involving Type 1 diabetes-affected sib-pairs [10] or the NOD mouse. The obvious message for the genetics of human Type 1 diabetes is that a range of non-MHC genes are implicated, all of which influence $\mathrm{T}$ cell activation and survival in the presence of the appropriate MHC (all susceptible rat strains express $R T 1^{u}$ class II alleles).

Understanding the genetic basis of diabetes in rodent models will pay dividends with regard to the genetics of Type 1 diabetes in humans. Availability of molecular reagents to study both MHC class II and class I interactions with $\mathrm{T}$ cell receptors of diabetogenic $\mathrm{CD} 4$ and $\mathrm{CD} 8 \mathrm{~T}$ cell clonotypes isolated from the NOD pancreas has proved invaluable for understanding the pathogenic complexity of MHC contributions. Human geneticists accept that HLA-linked susceptibility extends beyond the $D R / D Q$ susceptibility alleles. Given the difficult problem of linkage disequilibrium, elucidation of the additional MHC-linked susceptibility contributors shown to be linked to the diabetogenic $\mathrm{H} 2^{\mathrm{g} 7}$ complex of the NOD mouse may provide the necessary candidate genes for further progress. Although the various rodent models present us with different sets of non-MHC susceptibility genes, some of the phenotypes are strikingly similar. Defects in the innate immune systems of the NOD mouse and the BB rat are now well described, including defects in maturation and function of natural killer cells, macrophages, and dendritic cells. Diabetes in the NOD mouse is a "default pathway" activated only in the absence of natural encounters with the microbial environment [11]. Hence, the NOD mouse should not be used to test pathogenic viruses as natural environmental triggers. In this situation the model of choice would be the diabetes-resistant BB rat, in which certain viruses clearly act to trigger immunemediated diabetes when $\mathrm{T}$ cells are transiently depleted [12]. It remains to be seen whether this heterogeneity is reflected in the multiplicity of genotypes inherited by humans with Type 1 diabetes, but elucidating the mechanisms underlying spontaneous diabetes de- 
velopment in each unique animal model allows special insight into potential pathways leading to Type 1 diabetes in humans.

There are several areas in which animal models have taught us a great deal, and we continue to learn more. The first is investigation of immune responses at locations that are not readily accessible in humans, such as the islets and the pancreatic draining lymph nodes. These locations are crucial for understanding disease pathogenesis, since human studies are largely restricted to comparison of changes in peripheral blood leucocyte functions, distinguishing affected individuals from case controls. Analysis of leucocyte trafficking in animal models has demonstrated the importance of the pancreatic lymph node for activation of certain T effectors, and of the vascular endothelium surrounding the islets for the activation of others [13, 14].

Secondly, it is difficult to establish proof of concept in humans. Except for studies involving human knock-outs and other diseases caused by one or very few genetic changes, we have experienced substantial difficulties in analysing more complicated immunological processes in humans. In contrast, animal models lend themselves to the design of crucial proofof-concept studies, since they allow for adoptive transfer studies, deletion of $\mathrm{T}$ or $\mathrm{B}$ cell populations and targeted genetic knock-out investigations. Strategies such as these have been used to elucidate the molecular requirements for in vivo migration and effector functions of lymphoid cell populations $[15,16]$.

Thirdly, animal experimentation is needed to define possible dose ranges and regimens for immune therapies. Many, if not all, immune or antigen-based interventions under evaluation for future human therapy operate best at a closely defined dose range. To detect such dose-response associations, as well as to elucidate the underlying mechanisms and to develop the best candidates, animal models remain indispensable. One can envision that once sufficient knowledge has been gathered about the immune system and a given disease, computer simulations may begin to substitute animal experimentation, but that day is still far away.

Care must be exercised when extrapolating experimental outcomes from animal models to humans. Findings in a single animal model (usually the NOD mouse) have been taken to clinical trials in humans without exploring the finding in other suitable animal models. For example, the therapies produced in NOD mice by GAD or its peptides are rarely reported for any of the rat models, even though rat islets are much more "human" in terms of the levels of GAD protein expressed in beta cells [17]. Similarly, favourable results using Hsp60 peptide 277 or nicotinamide in suppressing diabetes in NOD mice have not been followed up with trials in the rat models. Even when data from both mouse and rat models support extrapolation of a therapy into the human arena (for example, insu- lin prophylactic treatment), extreme caution must still be exercised. In a recent example, more insulin was required for diabetes retardation in the NOD mouse than could safely be administered to prediabetic children [18]. Ongoing comparisons between findings in different animal models and human patients are thus essential. However, one still frequently hears that a certain scientific discovery can be considered a universal truth because it was found to be true in the NOD mouse. The knowledge that viruses can trigger diabetes in some rat models [19] implies that, as must be the case in humans, there is important heterogeneity among animal models with regard to the specific nature of the immunogenetic interactions with microbial elements, including viruses that lead to clinical disease [20].

\section{Can we generalise our findings or does one mouse model equal one human patient?}

How far-reaching should the conclusions be that we draw from observations in a given animal model? We advise greater caution than is usual in the current literature. The prevailing attitude is still that once a discovery has been made in one of the animal models thought to represent the human disease faithfully (i.e. the NOD mouse for diabetes, the experimental allergic encephalitis mouse model for multiple sclerosis or the NZB $\times$ NZW mouse model for systemic lupus erythematosus), there is no urgent need to look at this issue in other model systems. If the same result is found, it is considered 'confirmatory', if a different result is discovered, the 'secondary' model is frequently labelled as not as good or even flawed, for which various reasons are then cited. We believe that this can be treacherous, and might hamper translation of research performed in animal models. A good example is the tremendous popularity of the NOD mouse as a model of diabetes. Among the reasons for this popularity are the spontaneous disease onset in a genetically wellcharacterised genus and the wide array of genetic tools and immunogenetic reagents available for studying the model. However, despite the many commonalities listed in Table 1, the precipitating causes of diabetes in humans versus NOD mice may well differ. It is surely more accurate to approach this topic with the attitude that each animal model will only reflect certain aspects of a disease well. If one presumes that there is significant heterogeneity in the pathogenesis, manifestation and clinical course of Type 1 diabetes, multiple sclerosis or other autoimmune diseases, then, at best, each model will reflect a fraction of cases well. For example, few patients exhibit all the clinical features of the NOD mouse, which include progressive hearing loss, haemolytic anaemia, widespread deficiencies in the innate immune system, and a polyglandular spectrum of autoimmune syndromes affect- 
ing thyroid and salivary glands [21]. There are, however, some striking similarities, for example the occurrence of autoantibodies that presage the development of clinical disease in both NOD mice and humans [22]. It follows that we should emphasise the importance of validation of crucial findings in other model settings. This will to some extent necessitate a change in culture.

In summary, there are, of course, discrepancies between animal models and the human disease. For example, CD154 (CD40 ligand) blockade works well in rodents but not in humans because of unanticipated CD154 expression on human platelets. Even so, and despite the fact that a comparable reagent that works well in an NOD mouse may not yet be available for use in humans, the animal work provides a "roadmap" indicating possible routes to transplantation tolerance. For example, successful establishment of the nonmyeloablative protocols necessary to achieve bone marrow allochimerism and subsequent islet transplantation tolerance in NOD mice in conjunction with CD154 blockade [23] will be very likely to inform comparable efforts in humans when a suitable reagent for co-stimulation blockade is developed.

In conclusion, the best response to those who challenge the relevance of animal research in Type 1 diabetes is simple. Just ask yourself this: how much would we understand about this condition if animal models of immune-mediated diabetes did not exist?

\section{References}

1. Roep BO, Atkinson MA (2004) Animal models have little to teach us about diabetes: 1. In support of this proposal. Diabetologia 47:DOI 10.1007/s00125-004-1517-1

2. Mestas J, Hughes CC (2004) Of mice and not men: differences between mouse and human immunology. J Immunol 172:2731-2738

3. Rossini AA (1998) Autoimmune diabetes and the circle of tolerance. Diabetes 53:267-275

4. Komeda K, Noda M, Kanazawa M, Terao K, Kanazawa Y, Kuzuya N (1998) Establishment of 2 substrains, diabetesprone and nondiabetic, from Long-Evans Tokushima-Lean (LETL) rats. J Endocrinol 45:737-744

5. Lenzen S, Tiedge M, Elsner M et al. (2001) The LEW.1AR1/Ztm-iddm rat: a new model of spontaneous insulin-dependent diabetes mellitus. Diabetologia 44:11891196

6. Serreze DV, Leiter EH (1995) Insulin dependent diabetes mellitus (IDDM) in NOD mice and BB rats: origins in hematopoietic stem cell defects and implications for therapy. In: Shafrir E (ed) Lessons from animal diabetes V. SmithGordon, London, pp 59-73
7. Ueda H, Howson JM, Esposito L et al. (2003) Association of the T-cell regulatory gene CTLA4 with susceptibility to autoimmune disease. Nature 423:506-511

8. Pandarpurkar M, Wilson-Fritch L, Corvera S et al. (2003) Ian4 is required for mitochondrial integrity and $\mathrm{T}$ cell survival. Proc Natl Acad Sci USA 100:10382-10387

9. Yokoi N, Komeda K, Wang HY et al. (2002) Cblb is a major susceptibility gene for rat type 1 diabetes mellitus. Nat Genet 31:391-394

10. Payne F, Smyth DJ, Pask R et al. (2004) Haplotype tag single nucleotype 1 diabetes polymorphism analysis of the human orthologues of the rat type 1 diabetes genes Ian 4 (Lyp/Iddm1) and Cblb. Diabetes 53:505-509

11. Atkinson MA, Leiter EH (1999) The NOD mouse model of type 1 diabetes: as good as it gets? Nat Med 5:601604

12. Mordes JP, Groen H, Bortell R, Greiner DL, Rossini AA (2001) Autoimmune diabetes mellitus in the BB rat. In: Sima AAF, Shafrir E (eds) Animal models of diabetes: a primer. Harwood, Amsterdam, pp 1-41

13. Mathis D, Vence L, Benoist C (2001) Beta-cell death during progression to diabetes. Nature 414:792-798

14. Savinov AY, Wong FS, Stonebraker AC, Chervonsky AV (2003) Presentation of antigen by endothelial cells and chemoattraction are required for homing of insulin-specific CD8+ T cells. J Exp Med 197:643-656

15. Kilshaw PJ, Higgins JM (2002) Alpha E: no more rejection? J Exp Med 196:873-875

16. Kommajosyula S, Reddy S, Nitschke K, Kanwar JR, Karanam M, Krissansen GW (2001) Leukocytes infiltrating the pancreatic islets of nonobese diabetic mice are transformed into inactive exiles by combinational anti-cell adhesion therapy. J Leukoc Biol 70:510-517

17. Bridgett MM, Cetkovic-Cvrlje M, Narayanswami S et al. (1998) Differential protection in two transgenic lines of NOD/Lt mice hyperexpressing the autoantigen GAD65 in pancreatic beta cells. Diabetes 47:1848-1856

18. Karounos DG, Goes SE, Bryson JS (2003) Dose of insulin is a critical factor in the prevention of Type 1 diabetes in the NOD mouse. Diabetes 52 [Suppl 2]:A276

19. Zipris D, Hillebrands JL, Welsh RM et al. (2003) Infections that induce autoimmune diabetes in BBDR rats modulate CD4(+)CD25(+) $\mathrm{T}$ cell populations. J Immunol 170:3592-3602

20. Herrath MG von, Oldstone M, Homann D, Christen U (2001) Is activation of autoreactive lymphocytes always detrimental? Viral infections and regulatory circuits in autoimmunity. In: Herrath MG von (ed) Molecular pathology of Type 1 diabetes mellitus. Karger, New York, pp 91-122

21. Leiter EH, Atkinson MA (1998) NOD mice and related strains: research applications in diabetes, AIDS, cancer, and other diseases. Medical Intelligence Unit. RG Landes, Austin, p 208

22. Pietropaolo M, Eisenbarth GS (2001) Autoantibodies in human diabetes. Curr Dir Autoimmun 4:252-282

23. Nikolic B, Takeuchi Y, Leykin I, Fudaba Y, Smith RN, Sykes M (2004) Mixed hematopoietic chimerism allows cure of autoimmune diabetes through allogeneic tolerance and reversal of autoimmunity. Diabetes 53:376-383 